\title{
AVALIAÇÃO DO EFEITO DAS ÁGUAS SUPERFICIAIS DOS ESTUÁRIOS DOS RIOS CAMBORIÚ E ITAJAÍ-AÇÚ SOBRE O CRESCIMENTO DA DIATOMÁCEA Skeletonema costatum
}

\author{
MACEDO, R.S.; RÖRIG, L.R.; URBAN, S.R.; CASTRO-SILVA, M.A. da; PEREIRA-FILHO, J. \\ CENTRO DE CIÊNCIAS TECNOLÓGICAS DA TERRA E DO MAR - CTTMar - UNIVALI
}

\begin{abstract}
Macedo, R.S.; Rorig, L.R.; Uurban, S.R.; Castro-Silva, M.A. da; Pereira-Filho, J. 2005. Evaluation of estuarine surface waters effect on grouth of diatom Skeletonema costatum. Braz. J. Aquat. Sci. Technol. 9(2):9-15. ISSN 1808-7035. The Itajaí-Açú and Camboriú rivers are the main important water suppliers for domestic and agroindustrial use in Itajaí and Balneário Camboriú cities in southeastern coast of Brazil. The waste dispoasal by human activities in these estuaries may result in poor water quality and even prevent its use for these activities. In order to evaluate the effects of the human activities upon the estuaries water quality, this study was carried out to evaluate and compare the surface water quality in both estuaries, using a toxicological bioassay to mesure the effect of these waters in growth of marine microalgae Skeletonema costatum (Bacillariophyceae). The samples were colletcted from august of 2003 to march of 2004 in every two weeks at CEPSUL/IBAMA pier (in Itajaí-Açú estuary) and turistic pier (in Camboriú estuary). The physical and chemical characteristics of the samples were determined in situ. The samples were taken to laboratory and frozen for further use. After conducing the bioassay, the results show an increase in algal growth due to excess of nutrients in the samples of both estuaries. This result indicates water eutrophication, as reported in other studies. No effect in the growth of the species was observed for the samples collected in summer months. The samples of march of 2004 from Camboriú estuary were toxic to S. costatum. This result may be due to the disposal of treated wastewater from Balneário Camboriú wastewater treatment plant in the surface river water. The observed concentration effect (CEO) obtained for the samples of march were almost $50 \%$. The $\mathrm{CE}_{50}$ calculated was $96,17 \%$ for one sample of march. In the present work, the use of microalgae toxicity test for mesure toxicity in environmental samples and its use as water eutrophication indicator were confirmed.
\end{abstract}

Keywords: ecotoxicology, estuary, Itajaí-Açú, Camboriú, eutrophication.

\section{INTRODUÇÃO}

O estado de Santa Catarina tem a maioria da sua população e grande parte das atividades econômicas concentradas na região costeira, o que torna esta região bastante suscetível a eventuais impactos ambientais gerados pela disposição excessiva de contaminantes oriundos de todas estas atividades. As bacias dos rios Camboriú e Itajaí-Açú (litoral centronorte do estado) são utilizadas para diversas atividades agrícolas e urbanas. No caso específico do rio Itajaí-Açú, somam-se as atividades portuárias e industriais. Segundo Bishop (1983), os contaminantes tendem a se concentrar nas regiões estuarinas em resposta ao comportamento em conjunto das forçantes fluviais e marítimas, o que torna estes ecossistemas constantemente expostos a eventuais ações deletérias de compostos de diferente natureza.

Os contaminantes, principalmente os persistentes, tendem a se acumular no ambiente e nos organismos e geram modificações nas características químicas, da qualidade da água e alterações nas comunidades biológicas. As substâncias não persistentes, ou degradáveis, promovem um aporte de nutrientes que favorece certos níveis tróficos causando um desequilíbrio dentro da composição das comunidades e do ambiente (Schäfer, 1984). O efeito destes contaminantes sobre os sistemas vivos pode ser mensurado, através de ensaios ecotoxicológicos que medem a concentração das substâncias tóxicas presentes no meio, suficiente para lhes causar efeitos deletérios.

No mundo inteiro os ensaios ecotoxicológicos já são realizados há bastante tempo e ganham cada vez mais espaço dada a limitação das análises puramente físico-químicas. No Brasil, a aplicação deste tipo de teste ainda é recente e muitos ecossistemas poluídos no país ainda carecem de ser estudados sobre esta abordagem. Dentre os trabalhos feitos pode-se salientar aquele realizado por Aidar et al. (1999), que avaliaram a toxicidade da água de produção de dois efluentes de um terminal marítimo de óleo sobre a microalga Skeletonema costatum. Alves et al. (2000), também utilizando S. costatum, realizaram uma avaliação ecotoxicológica, dos efluentes da Companhia Siderúrgica de Tubarão (Vitória, ES) antes e depois das melhorias em um sistema de tratamento de amônia.

Nos estuários dos rios Itajaí-Açú e Camboriú foram feitos poucos trabalhos envolvendo a utilização de 
ensaios ecotoxicológicos, como os feitos por Laitano $\&$ Resgalla Jr. (2000), que avaliaram qualidade do sedimento dos rios Camboriú e Itajaí-Açú, através de testes de toxicidade crônica, utilizando larvas de Arbacia lixula, e aguda, com juvenis de Metamysidopsis elongata atlântica.

O presente trabalho apresenta resultados de ensaios ecotoxicológicos com a microalga marinha Skeletonema costatum, uma espécie bastante representativa e de importância ecológica em águas costeiras, para traçar um comparativo do impacto potencial da poluição entre os dois estuários, que é de origem diferente, sobre os organismos produtores primários, e também verificar a sensibilidade deste teste para avaliar estes tipos de poluição.

Área de estudo

Os estuários dos rios Itajaí-Açú e Camboriú localizam-se no litoral centro-norte do estado de Santa Catarina, situados, respectivamente, onde está o maior porto pesqueiro do país e na região de um dos maiores pólos turísticos do Mercosul. Comparando as bacias dos rios Itajaí-Açú e Camboriú, nota-se uma diferença quanto ao tipo de atividade que é desenvolvida em cada uma e, conseqüentemente, uma diferença quanto aos tipos preponderantes de resíduos que entram nos dois estuários.

\section{Estuário do rio Itajaí-Açú:}

O estuário do rio Itajaí-Açú é a única vertente para o mar de toda a bacia, sendo delimitado ao sul pela cidade de Itajaí e ao norte pela cidade de
Navegantes (Figura 1). A principal atividade econômica da região é o comércio, particularmente o Porto de Itajaí, seguido pela indústria de transformação de pescados e pelo turismo de temporada (Comitê do Itajaí, 2003). Os principais tipos de fontes de poluição identificadas são os efluentes domésticos, industriais (têxteis, indústria de pescado, laboratórios fotográficos) e diversas canalizações provenientes de áreas rurais ou áreas peri-urbanas, além da atividade portuária propriamente dita (Rörig et al., 2003).

\section{Estuário do rio Camboriú:}

O estuário do rio Camboriú localiza-se no município de Balneário Camboriú (SC), cidade considerada como o maior pólo turístico do sul do Brasil (Figura 2). O estuário do rio Camboriú originalmente tinha grande importância para a pesca artesanal servindo de subsistência para a comunidade local. Atualmente, a água do rio e seus tributários são utilizadas para o desenvolvimento agropecuário e abastecimento da população (Urban, 2002). As atividades agropecuárias, onde destaca-se a produção de arroz, e o comércio de temporada são as principais atividades econômicas da região.

As atividades ligadas à agricultura e os esgotos domésticos e de estabelecimentos comerciais, que em muitos locais não recebem tratamento suficiente e/ou adequado, são as maiores fontes da contaminação das águas do estuário e da enseada de Balneário Camboriú. Nos meses de verão, esta contaminação tende a se tornar mais evidente, pois a estação de tratamento de esgoto do município não foi projetada para suportar o excedente populacional (Kuroshima et al., 1996).

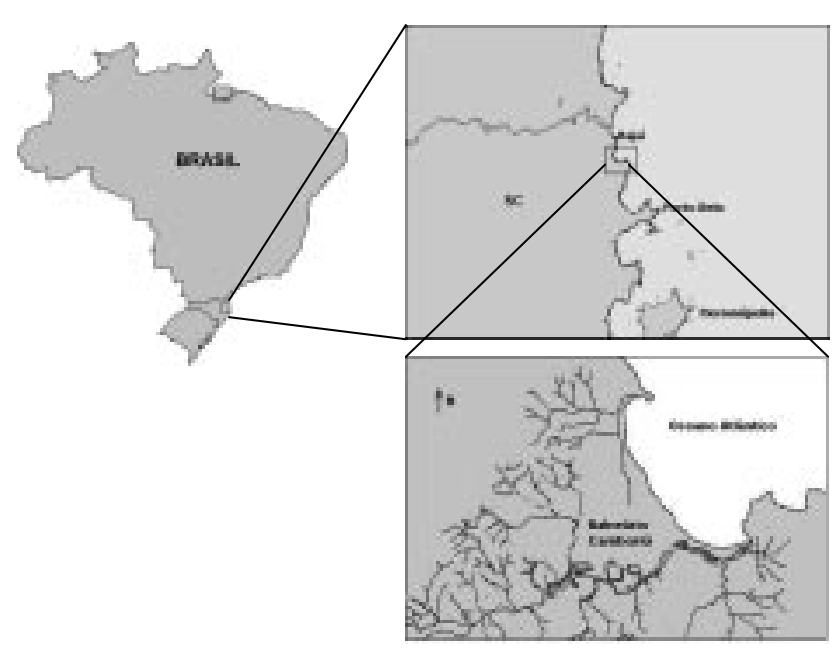

Figura 2 - Localização da bacia do rio Camboriú e ponto amostral com localização indicada pela seta.
Figura 1 - Localização da região do Baixo Vale do estuário do rio Itajaí-Açú e ponto amostral com localização indicada pela seta.

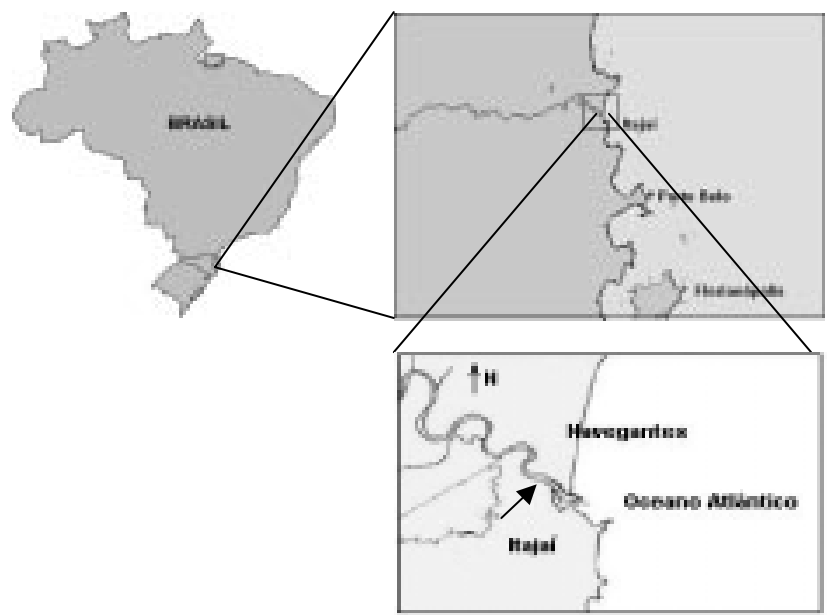




\section{MATERIAIS E MÉTODOS}

As amostras de água superficial no estuário do rio Itajaí-Açú foram coletadas junto ao píer de atracação do Cepsul - IBAMA, no centro de Itajaí (Figura 1) e junto ao pier turístico no estuário do rio Camboriú (Figura 2). As amostras foram coletadas sempre entre 13 e 14 horas. Foram realizadas amostragens quinzenais que se estenderam desde o mês de agosto até março de 2004. No momento da coleta foram medidos os parâmetros físico-químicos da água (salinidade, condutividade, $\mathrm{pH}$, oxigênio dissolvido, temperatura e turbidez) através de uma sonda multiparâmetro (Horiba - H10), para verificar correlações com os resultados do ensaio ecotoxicológico e com a concentração de nutrientes disponibilizadas pelo Laboratório de Ocenografia Química do Centro de Ciências Tecnológicas da Terra e do Mar (CTTMar) da Universidade do Vale do Itajaí (UNIVALI).

O experimento foi realizado segundo normas protocoladas da ISO (1989). As amostras foram filtradas em filtro GF/F 0,47 ìm antes da realização do experimento. Foram utilizados para os ensaios frascos erlenmeyer de $250 \mathrm{~mL}$. Em cada frasco foram feitas as diluições correspondentes das amostras de água superficial, utilizando meio de cultivo, e um inóculo algal em crescimento exponencial gerando um volume final de aproximadamente $150 \mathrm{~mL}$ por frasco. Em cada amostra foram adicionados nutrientes na mesma concentração do meio de cultivo, de modo que a concentração de nutrientes adicionados em laboratório não foi alterada ao longo das diluições. Os frascos controle (ou provas em branco) consistiram de meio de cultivo puro. Os tratamentos utilizados foram $100 \%$ mais duas diluições (50\% e 10\%), e os controles para cada amostra, sempre em triplicata.

Todas as amostras tiveram a salinidade corrigida para 31\%, que é a salinidade em que os inóculos algais eram mantidos. Como a salinidade das amostras foi aumentada utilizando-se de salmoura, estas não poderam ser mais tratadas como $100 \%$ de amostra pura e sim como uma diluição dependente do volume de salmoura adicionado. A concentração final média das amostras após as diluições e a adição de salmoura ficou em aproximadamente $80 \%$.

Após a montagem do bioensaio, foi feita uma leitura inicial de fluorescência de clorofila-a. Os frascos foram mantidos em agitação por 72 horas sob luminosidade de $80 \mathrm{mE} / \mathrm{cm}^{2} / \mathrm{s}$, temperatura de $20 \pm 2^{\circ} \mathrm{C}$ e pH entre 7,0 e 8,0. Após o término do tempo de exposição foi feita uma leitura final de fluorescência de clorofila-a. As leituras de fluorescência foram feitas em um fluorímetro Turner Designs TD700.

Com os dados obtidos de fluorescência foram calculadas as taxas de crescimento em cada tratamen- to através da equação 1 . As taxas de crescimento obtidas nos tratamentos foram comparadas com as taxas de crescimento obtidas nos frascos controle e assim calculados os percentuais de inibição do crescimento em relação ao controle (equação 2 ).

$$
\mu=\frac{L n N n-L n N o}{t n}
$$

onde:

$\mu$ é a taxa de crescimento celular;

No é a leitura de fluorescência inicial;

Nn é a leitura de fluorescência final;

tn é o tempo decorrido desde o início do teste.

$$
I \mu_{i}=\frac{\mu c-\mu i \times 100}{\mu c}
$$

onde:

$I \mu_{\mathrm{i}}$ é a percentagem de inibição para o teste na concentração i;

$m_{i}$ é a taxa de crescimento médio para o teste na concentração i;

$m_{c}$ é a taxa de crescimento para o controle.

Os valores de taxa de crescimento em cada tratamento foram comparados com a taxa de crescimento observada no controle através de uma análise de variância (ANOVA) aplicada pelo aplicativo Toxstat. Com a aplicação da ANOVA foi possível estimar os parâmetros ecotoxicológicos concentração de efeito não observado (CENO) e concentração de efeito observado (CEO). Os valores de concentração efetiva mediana $\left(\mathrm{CE}_{50}\right)$ foram obtidos através do aplicativo Trimmed Spearman-Karber.

\section{RESULTADOS E DISCUSSÃO}

O efeito mais observado foi o de estímulo de crescimento da espécie Skeletonema costatum, o que gerou valores negativos para o percentual de inibição em relação ao controle, calculado pela Equação 2. Os valores de percentual de inibição de crescimento nos tratamentos foram negativos na maioria das datas de coleta tanto para o rio Itajaí-Açú (figura 3) como para o rio Camboriú (figura 4). Isto já era esperado, pois as concentrações de nutrientes presentes nas amostras se somam às concentrações de nutrientes adicionados em laboratório. Estas últimas permanecem constantes ao longo das diluições, de modo que a diferença de crescimento entre cada amostra e entre cada tratamento é resposta a mudanças nas concentrações de nutri- 


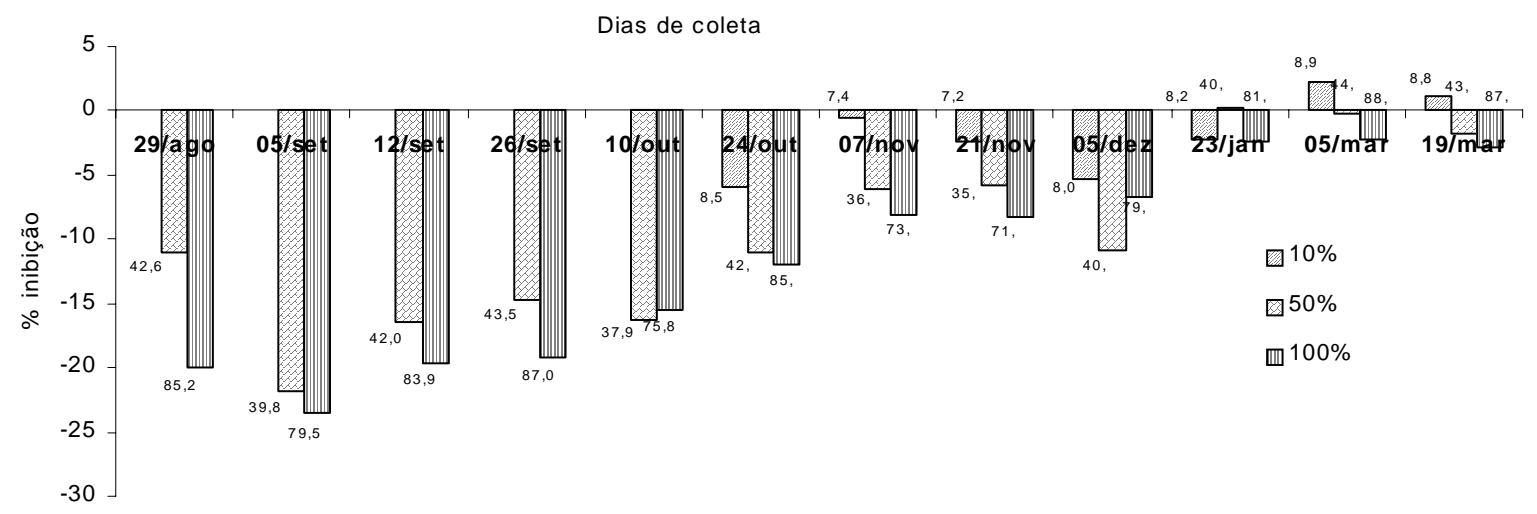

Figura 3 - Percentual de inibição em relação ao controle nos diferentes dias de coleta para o ponto amostral no estuário do rio Itajaí-Açú; os valores sobre as barras referem-se às concentrações finais após a adição de salmoura.

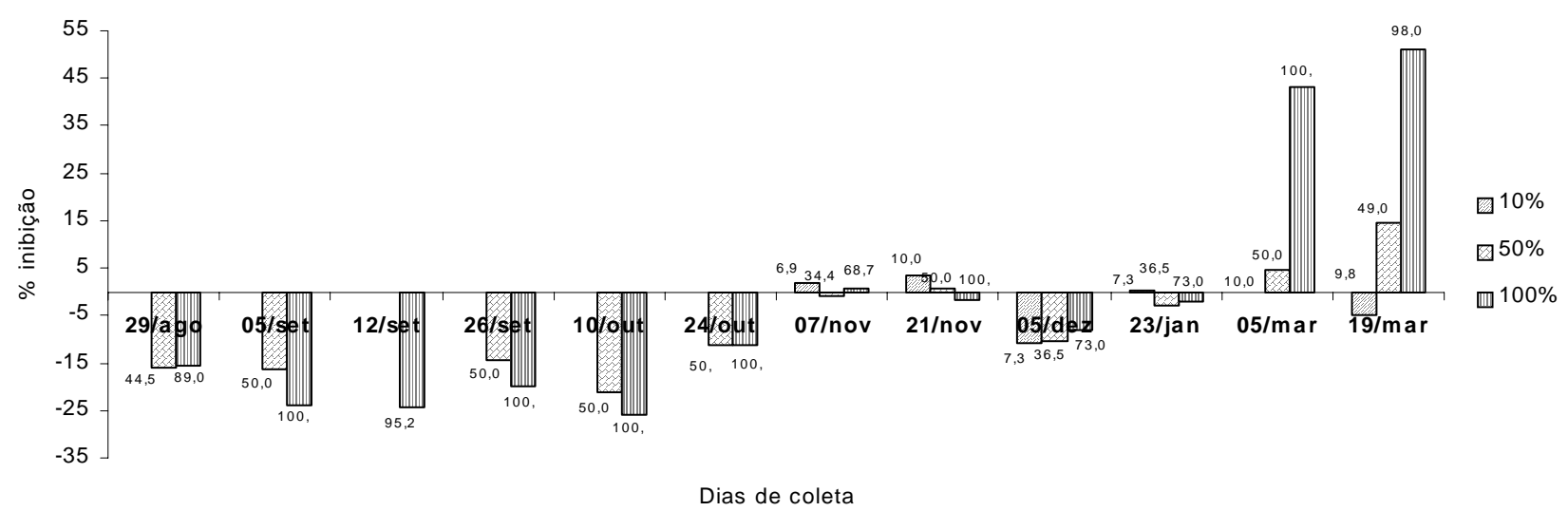

Figura 4 - Percentual de inibição em relação ao controle nos diferentes dias de coleta para o ponto amostral no estuário do rio Camboriú; os valores sobre as barras referem-se às concentrações finais após a adição de salmoura.

entes oriundos da própria amostra. Houve uma maior taxa de crescimento nos tratamentos em praticamente todas as amostras, o que sugere uma grande disponibilidade de nutrientes na água de ambos os rios, caracterizando um certo potencial para eutrofização das águas destes estuários.

Para o rio Itajaí-Açú, a amostra do dia 05/09/ 2003 foi a que apresentou maior crescimento, aproximadamente $23 \%$ a mais que o controle na concentração de 79,5\% (Figura 5). Para o rio Camboriú, o maior crescimento foi no dia 10/10/2003, aproximadamente $26 \%$ a mais que o controle na concentração de $100 \%$. As amostras referentes ao mês de março de 2004 do rio Camboriú mostraram inibição de crescimento algal.

Para o rio Itajaí-Açú os valores mais baixos de CENO e CEO foram de $7,14 \%$ e $35,68 \%$, respectivamente, no dia 21/11/2003 e os valores mais altos foram de $42,63 \%$ (CENO) e 85,25 (CEO) no dia 29/08/2003. Para o rio Camboriú poucos valores de CENO puderam ser determinados, já que as menores concentrações testadas já apresentaram efeito significativo no cresci- mento algal. O menor valor de CEO foi de $7,30 \%$ no dia $05 / 12 / 2003$ e o maior valor foi de $50,0 \%$. Em ambos os estuários, a maioria dos valores de CEO foram aproximadamente $50 \%$ da concentração final das amostras.

As únicas duas amostras que apresentaram toxicidade foram da água superficial do rio Camboriú, coletadas no mês de março de 2004. As amostras dos dias 05/03 e 19/03/2004 mostraram-se tóxicas a aproximadamente $50 \%$ (CEO). Os valores de CENO foram de $10 \%$, para o dia $05 / 03 / 2004$, e $9,8 \%$ para o dia $19 /$ 03/2004 (Tabela 1). O valor de $\mathrm{CE}_{50}$ para o dia 05/03/04 não pôde ser calculado já que o máximo percentual de inibição nesta data foi de $43,2 \%$ na concentração de 100\%. Para o dia 19/03/04 a CE ${ }_{50}$ foi de $96,17 \%$.

A análise de correlação entre o estímulo de crescimento algal, os parâmetros físico-químicos e nutrientes (Tabela 2) das amostras do estuário do rio ItajaíAçú mostrou relação inversa entre a o estímulo de crescimento algal e a temperatura da água $(r=-0,7485)$. A temperatura da água apresentou relação inversa com a concentração de amônio $(r=-0,6657)$. Houve uma rela- 

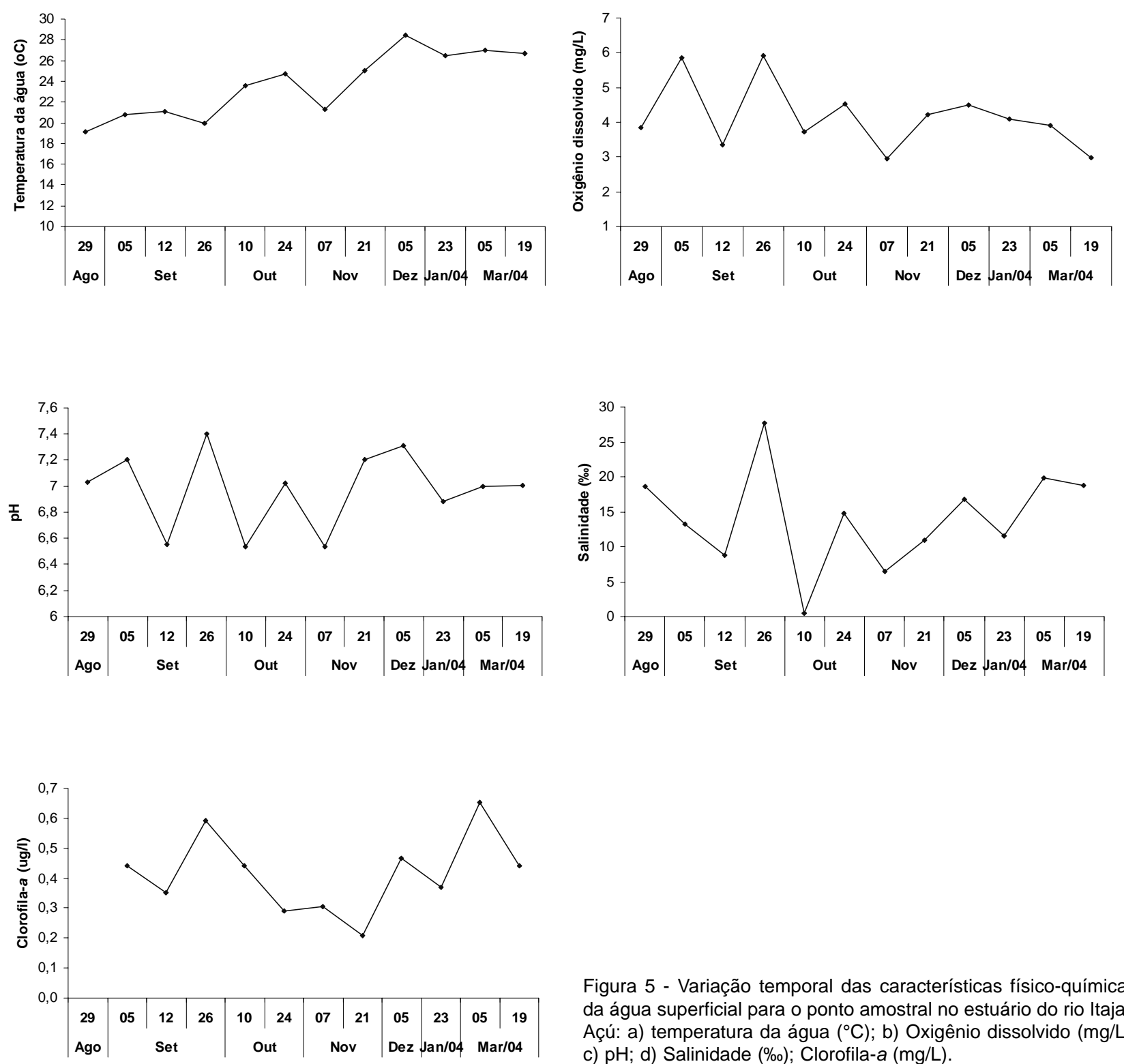

Figura 5 - Variação temporal das características físico-químicas da água superficial para o ponto amostral no estuário do rio ItajaíAçú: a) temperatura da água $\left({ }^{\circ} \mathrm{C}\right)$; b) Oxigênio dissolvido ( $\left.\mathrm{mg} / \mathrm{L}\right)$; c) $\mathrm{pH}$; d) Salinidade (\%o); Clorofila-a (mg/L).

ção direta entre o estímulo de crescimento e a concentração de amônio $(r=0,6909)$. Dentre os nutrientes analisados este composto foi o único que esteve associado ao crescimento algal de forma mais coerente sugerindo que é principalmente este composto o responsável pela variação no crescimento obtido para esta espécie. O amônio ainda apresentou relação direta com a clorofila-a do ambiente (Tabela 3).

Para o rio Camboriú não estão disponíveis os valores das concentrações de nutrientes, contudo, existem trabalhos anteriores sobre a dinâmica de nutrientes na região. Pereira-Filho et al. (2002) encontraram

valores elevados para estes elementos, evidenciando uma condição de eutrofização deste estuário quando comparado a outros estuários impactados como o do rio Itajaí-Açú. Em estudos anteriores, este último apresentou elevadas concentrações de amônio em diferentes situações de variação de maré o que pode estar associado à carga de poluentes de origem doméstica (Spillere et al., 2000 e Pereira-Filho et al., 2002). A tendência à eutrofização em ambos os estuários, está sendo confirmada pelos resultados obtidos neste trabalho. A maioria das amostras estimulou o crescimento da microalga S. costatum, que foi promovido pela 
Macedo et al:: Efeito de águas superficiais estuarinas sobre o crescimento de Skeletonema costatum.

Tabela 1 - Valores de CENO e CEO para as amostras dos estuários do rio Itajaí-Açú e Camboriú; os valores em negrito indicam efeito de toxicidade.

\begin{tabular}{ccccc}
\hline & \multicolumn{2}{c}{ Estuário do rio Itajaí-Açú } & \multicolumn{2}{c}{ Estuário do rio Camboriú } \\
\cline { 2 - 5 }$\#$ & CENO (\%) & CEO (\%) & CENO (\%) & CEO (\%) \\
\hline $29 / 08 / 03$ & 42,63 & 85,25 & - & 44,48 \\
$05 / 09 / 03$ & - & 39,78 & - & 50 \\
$12 / 09 / 03$ & - & 41,96 & - & - \\
$26 / 09 / 03$ & - & 43,49 & - & 50 \\
$10 / 10 / 03$ & - & 37,89 & - & 50 \\
$24 / 10 / 03$ & 8,51 & 42,53 & - & 50 \\
$07 / 11 / 03$ & 7,38 & 36,89 & - & - \\
$21 / 11 / 03$ & 7,14 & 35,68 & - & - \\
$05 / 12 / 03$ & 7,97 & 39,84 & - & 7,30 \\
$23 / 01 / 04$ & - & - & - & - \\
$05 / 03 / 04$ & - & - & $\mathbf{1 0}$ & $\mathbf{5 0}$ \\
$19 / 03 / 04$ & - & - & $\mathbf{9 , 8}$ & $\mathbf{4 9 , 0 2}$ \\
\hline
\end{tabular}

Tabela 2 - Valores de concentração dos principais nutrientes para amostras do rio Itajaí.

\begin{tabular}{cccccc}
\hline$\#$ & $\mathrm{NH}_{4}{ }^{+}$(uM) & $\mathrm{NO}_{2}{ }^{-}(\mathrm{uM})$ & $\mathrm{NO}_{3}{ }^{-}$(uM) & $\mathbf{P O}_{4}{ }^{3-}{ }^{-}(\mathrm{uM})$ & $\mathrm{Si}(\mathrm{uM})$ \\
\hline $29 / 08 / 03$ & 58,0 & 1,6 & & 1,0 & 166,6 \\
$05 / 09 / 03$ & 64,2 & 1,6 & 26,4 & 1,4 & 114,9 \\
$12 / 09 / 03$ & 52,5 & 1,4 & 26 & 0,9 & 94,1 \\
$26 / 09 / 03$ & & 0,9 & 12,1 & 1,3 & 118,2 \\
$10 / 10 / 03$ & & 2,4 & 95,7 & 1,6 & 22,7 \\
$24 / 10 / 03$ & 40,9 & 2,0 & 43,8 & 0,8 & 64,5 \\
$07 / 11 / 03$ & 55,5 & 1,7 & 46,2 & 0,5 & 9,2 \\
$21 / 11 / 03$ & 23,0 & 1,5 & 42,2 & 1,0 & 88,7 \\
$05 / 12 / 03$ & 47,7 & 1,1 & 16,6 & 1,0 & 74,5 \\
$23 / 01 / 04$ & 33,3 & 2,8 & 40,8 & 1,0 & 35,9 \\
$05 / 03 / 04$ & & 1,3 & 16,7 & 1,8 & 68,6 \\
$19 / 03 / 04$ & & 1,8 & 23,2 & 1,1 & 57,6 \\
\hline Máximo & 64,2 & 2,8 & 95,7 & 1,8 & 166,6 \\
Mínimo & 23,0 & 0,9 & 12,1 & 0,5 & 9,2 \\
Média & 46,9 & 1,7 & 35,4 & 1,1 & 76,3 \\
CV & 29,3 & 31,9 & 66,0 & 31,0 & 57,9 \\
\hline
\end{tabular}

Tabela 3 - Correlação entre os parâmetros físico-químicos, nutrientes e estímulo de crescimento algal nas amostras do rio Itajaí-Açú; $\mathrm{r}_{\text {tab }}$ $=0,632$, para $n=8$ e $p=0,05$.

\begin{tabular}{|c|c|c|c|c|c|c|c|c|c|c|c|c|}
\hline & CLA & TAG & OD & $\mathrm{PH}$ & SAL & COND & $\mathrm{NH} 4$ & $\mathrm{NO} 2$ & $\mathrm{NO} 3$ & $\mathrm{PO4}$ & SI & EST \\
\hline CLA & 1,0000 & & & & & & & & & & & \\
\hline TAG & & 1,0000 & & & & & & & & & & \\
\hline OD & & & 1,0000 & & & & & & & & & \\
\hline PH & & & 0,7733 & 1,0000 & & & & & & & & \\
\hline SAL & & & & 0,7237 & 1,0000 & & & & & & & \\
\hline COND & & & & 0,7284 & 0,9997 & 1,0000 & & & & & & \\
\hline NH4 & 0,6500 & $-0,6657$ & & & & & 1,0000 & & & & & \\
\hline NO2 & & & & & & & & 1,0000 & & & & \\
\hline NO3 & $-0,7717$ & & & & & & & & 1,0000 & & & \\
\hline PO4 & & & 0,8462 & 0,6546 & & & & & & 1,0000 & & \\
\hline SI & & & & & 0,6633 & 0,6660 & & & & & 1,0000 & \\
\hline EST & & $-0,7485$ & & & & & 0,6909 & & & & & 1,0000 \\
\hline
\end{tabular}

presença de nutrientes os quais, na sua maioria, têm origem relacionada aos resíduos orgânicos oriundos das atividades humanas.

A toxicidade encontrada para as amostras de março do estuário do rio Camboriú pode estar associada ao lançamento do efluente da Estação de Tratamento de Esgotos (ETE) de Balneário Camboriú (a principal fonte de poluição no estuário) em um local não muito distante do ponto amostral tratado neste trabalho. Como o lançamento deste efluente se dá de forma localizada, provavelmente o seu processo de diluição no corpo de água não ocorre eficientemente e o efeito poluidor acaba se manifestando na água superficial. Um estudo feito por Silva et al. (2000), mostrou que o efluente da ETE á altamente tóxico para a espécie $S$. costatum apresentando valores de $\mathrm{CE}_{50}$ entre $2 \%$ e $5 \%$ da concentração do efluente, o que é um indicativo que possivelmente o efeito poluidor do efluente esteja se manifestando na água superficial do estuário.
As amostras da água superficial do rio Itajaí-Açú, por sua vez, não apresentaram toxicidade. Isto pode estar relacionado ao fato de que como a cidade de Itajaí não possui uma estação de tratamento de esgotos, os efluentes chegam ao rio de forma difusa, o que pode facilitar a dissolução dos contaminantes pelo corpo aquático, especialmente se consideradas as dimensões desse estuário e a maior amplitude de influência marinha.

\section{CONCLUSÕES}

A cepa utilizada (diatomácea marinha Skeletonema costatum) mostrou-se sensível às águas superficiais e fontes poluidoras estudadas, podendo ser utilizada em ensaios tanto para determinação de efeitos de inibição de crescimento (toxicidade) como para efeitos de estímulo de crescimento (eutrofização). 
O resultado mais encontrado foi o efeito de eutrofização, sugerindo a presença excessiva de nutrientes oriundos da disposição intensa de resíduos orgânicos nas águas superficiais. O efeito de toxicidade só foi mensurado em duas ocasiões na água do estuário do rio Camboriú. São necessários estudos mais detalhados de monitoramento da água superficial e das fontes de poluição que atingem este estuário para verificar a origem da toxicidade encontrada e obter estimativas mais precisas da freqüência de ocorrência destes eventos.

\section{REFERÊNCIAS}

Aidar, E.; Sigaud-Kutner, T.C.S.; Bicego, M.C.; Schinke, K.P.; Gianesella, S.M.F. \& Braga, E.S. 1999. Evaluation of produced water toxicity from an oil maritime terminal through Skeletonema costatum toxicity tests. Revista Brasileira de Oceanografia. 47(2):137-144.

Alves, J.P.; Aguiar, W.V.; Effigen, J.I.; Sant' Ana, A.P.; Rossi, L.A. \& Assis, C.A. 2000. Avaliação Ecotoxicológica Utilizando Skeletonama costatum (Greville) Cleve (Bacillariophyceae) em Efluentes da Companhia Siderúrgica de Tubarão (CST), Antes e de Depois das Melhorias no Sistema de Tratamento de Amônia. In: Ecotoxicologia: Perspectivas para o Século XXI. São Carlos: RiMa. p. 343.

Bishop, P.L. 1983. Marine Pollution and its Control. McGraw-Hill.

Comitê do Itajaí-Açú. Localização e área. Disponível em: <http://www.comiteitajai.org.br/hp/bacia/> Acesso em: 15 maio 2003

ISO - International Organization for Standardization. 1989. Water Quality - Marine algae growth inhibition test with Skeletonema costatum and Phaedactylum tricornutum. Draft International Standard ISO/TC 147/SC 5/WG. Netherlands.

Kuroshima, K.N.; Bellotto, V.R.; Barreiro, M.A. \& Chevarria, G.G. 1996. Elaboração de um índice para monitoramento da qualidade da água na Enseada de Camboriú - SC. Anais do III Simpósio sobre Oceanografia-IOUSP.

Pereira-Filho, J.; Spillere, L.C.; Schettini, C.A.F. \& Silva, L.F. 2002. Estuário do rio Camboriú-SC: variação intramareal e transporte residual de nutrientes, COP e clorofila-a em condições de quadratura e sizígia. Notas técnicas Facimar, 6: 137-151.

Schafer, A. 1984. Fundamentos de Ecologia e Biogeografia das Águas Continentais. Porto Alegre: Ed. da Universidade UFRGS.

Silva, A.Z. Determinação do efeito do esgoto bruto e efluente da estação de tratamento de esgotos de Balneário Camboriú sobre o crescimento de Skeletonema costatum (Bacillariophyceae). Monografia apresentada no curso de graduação em Oceanografia da Universidade do Vale do Itajaí, para a obtenção do grau de Bacharel. Itajaí, 1999.

Spillere, L.; Pereira-Filho, J.; Schettini, C.A. \& Silva, L.F. 2000. Avaliação da variabilidade e transporte intramareal de nutrientes, COP e clorofila-a no estuário do rio Camboriú durante uma situação de maré de sizígia. p. 288-290. In: Anais da XIII Semana Nacional de Oceanografia: 500 anos de mar brasileiro. Itajaí: CTTMar.

Urban, S.R. Análise da qualidade da água da bacia do rio Camboriú, SC. Monografia apresentada no curso de graduação em Engenharia Ambiental da Universidade do Vale do Itajaí, para a obtenção do grau de Bacharel. Itajaí, 2002. 